\title{
Sorption models of Cadmium (11) ion onto edible fruit wastes
}

\author{
Okoro I.A. and Abii T.
}

\author{
Department of Chemistry, Michael Okpara University of Agriculture Umudike, \\ P.M B 7267 Umuahia, Abia State, Nigeria.
}

\begin{abstract}
Sorption models and sorption capacities of common edible fruit wastes for Cadmium (11) ion was investigated. The results of sorption studies showed that each of these common edible fruit waste sorbed more than ninety- six per cent of the Cadmium (11) ions from the aqueous solution. The results of the modelled isotherm equations namely Langmuir and Dubinin-Radushkevich showed that the maximum sorption capacity of each of these edible fruit wastes for Cadmium (11) ion Qmax I/g orange peels was great than that of the banana peels. The calculated energy value $E$ banana peels was great than that of the orange peels. Also the calculated porosity value $Q_{D} g / l$ banana peels was the great than that of the orange. The calculated Langmuir constant for the two edible fruit wastes was very close to unity.
\end{abstract}

Keywords: Cadmium (11) ion, sorption models, edible fruit wastes, biosorbent.

\section{INTRODUCTION}

Pollution and toxicity of Cadmium is well documented in literature. It is one of priority pollutants (1, 2).Cadmium is one of the inorganic contaminants of public health interest due to its high toxicity after accumulation in the organs of the human body and aquatic lives $(3,4)$.Cadmium in its ionic form as Cadmium (11) ion is present in low concentrations in several parts of the ecosystem namely ;human organs . human cells, animal cells, aquatic lives, sediments of underground water, and in surface water The maximum permissible of Cadmium (11) ion in the natural waters is about $0.005 \mathrm{ppm}$ (5).Cadmium (11) ion is chemically similar to Zinc(11) ion readily assimilated into the food chain (5, 3).Sources of Cadmium (11) ion are; batteries , alloys, pigments, plastics, cigarettes, contaminated irrigated water $(6,7,8)$. There is the need to develop a new method for the removal of Cadmium (11) ion from aqueous environment. The conventional methods for doing include; coagulation /filtration, ion-exchange, lime -softening and reverse osmosis $(9,10,11)$. These methods are costly not readily available and not environmentally friendly $(12,13$ 14$,$) . The need to develop new cost effective$ environmental friendly alternative method which is the subject of this study and the associated models therein. The use of biosorbents is the answer and the best alternative method currently in vogue $(15,16)$. These biosorbents are cheap, abundant, readily available and easy biodegradable. In this study two edible fruit wastes namely banana (Musa sapntium) peels, and sweet orange (Citrus sinesis) peels were used as biosorbent for the removal of Cadmium (11) ion from aqueous solution. The data thus obtained thereof was modelled using two isotherm equations namely; Langmuir and Dubinin-Radushkevich equations respectively.

Langmuir isotherm: This is used to calculate the sorption capacity of each of the biosorbent used for the removal of Cadmium (11) ion from the aqueous solution corresponding to complete monolayer coverage on the sorbent surface .This equation is expressed as

$\mathrm{Qe}=\mathrm{Qmax} \cdot \mathrm{KICe} / 1+\mathrm{KI} \cdot \mathrm{Ce}$

Where $\mathrm{Klg} / \mathrm{l}$ is a langmiur constant relating to the sorption energy, Qmax is the maximum sorption capacity of each of the biosorbents studied, and $\mathrm{Qe}$ is the amount of initial concentration of Cadmium (11) ion sorbed by each of the edible fruit wastes at contact time $t$.A Linear form of equation 1 after rearrangement given as

$\mathrm{Ce} / \mathrm{Qe}=1 / \mathrm{Qmax} \cdot \mathrm{KI}+\mathrm{Ce} / \mathrm{Qe}$

The experimental data obtained from the sorption studied for each of the edible fruit waste used as biosorbent shall be fitted into equation 2 by plotting the values of $\mathrm{Ce} / \mathrm{Qe}$ against the values of $\mathrm{Ce}$. The slop of this plot yields a reciprocal value of Qmaxl/g and the intercept of this plot gives the $\mathrm{KI}$ values.

Dubinin-Radushkevich isotherm: This equation is used to estimate the porosity value of each of biosorbents and the apparent energy $E$ of sorption for 
Cadmium (11) ion from aqueous solution. This equation is represented as

$\mathrm{Qe}=\mathrm{Q}_{\mathrm{D}}\left(\operatorname{Exp}_{-}-\mathrm{B}_{\mathrm{D}} \mathrm{R} \operatorname{T} \ln (1+1 / \mathrm{Ce})\right)^{2}$

Where $\mathrm{Qe}$ is the amount of Cadmium (11) ion sorbed by each of the biosorbents, QD is the DubininRadushkevich constant a measure of the porosity characteristics of each of these edible fruit wastes $B_{D}$ is used to calculate the apparent energy $E$ of sorption of Cadmium (11) ion from the aqueous solution using each of these biomass and $\mathrm{Ce}$ is the initial concentration of the Cadmium (11) ion solution. The linear form of equation 1 is given as

$$
\text { LnQe }=\ln Q_{D}-2 B_{D} R T(1+1 / C e)
$$

The experimental data obtained from the sorption studies was fitted into equation 4 by plotting the values of InQe against the values of $R T \ln (1+1 / \mathrm{Ce})$, at temperature of $25{ }^{\circ} \mathrm{C}$. The slop of this plot gives $2 \mathrm{~B}_{\mathrm{D}}$ which is used to calculate the apparent $\mathrm{E}$ for each of the biomass. The intercept of this plot yields the values of porosity $Q_{D}$ for each of these edible fruit waste biomass. The apparent energy $E$ is obtained as follows

E $=1 / \sqrt{ } 2 B_{D}$

In this study the models and sorption capacities of edible fruit waste biomass for the removal of Cadmium (11) ion from the aqueous solution are report.

\section{MATERIALS AND METHODS}

Sample collection: Banana (Musa sapentium) fruits and sweet orange (Critus sinesis) fruits were procured from the University of Agriculture Umudike demonstration orchards Umuahia Abia State Nigeria. All chemicals used are analytical grade reagents from $\mathrm{BDH}$ chemicals Itd London.

Sample preparation: The two edible fruits procured were washed clean, peeled manually with clean kitchen knife. Each of the peels was pooled together into labelled clean stainless trays. The content(s) of each tray was air-dried for 7 days. Then each tray further oven dried at $65^{\circ} \mathrm{c}$ for $24 \mathrm{hrs}$. Each dried peels was ground into powder using electric milling machine (Bina-ton model) .Each milled sample was sieved into fine powder using a 2-mm steel sieve. The sieved samples then stored in labelled clean bottles until they required for the sorption studies.

Preparation of Cadmium (11) ion solution: Cadmium chloride equivalent to 18.3 grams of Cadmium (11) ion was weighed out and taken into a one-litre volumetric flask; $25 \mathrm{ml}$ of deionised water was measured out and added into the flask shaken vigorously to achieve complete dissolution of the Cadmium chloride salt. The one-litre volumetric flask was made up to mark with deionised water to obtain one molar Cadmium (11) ion solution.

Sorption studies: To study the sorption capacity of each of the edible fruit wastes for Cadmium (11) ion a serial dilution of Cadmium (11) ion solution was carried out. The serial dilutions were $0.1 \mathrm{M}, 0.2 \mathrm{M}$, $0.4 \mathrm{M}$, and $0.6 \mathrm{M}$ Cadmium (11) ion solution equivalent to $1.83 \mathrm{~g} / \mathrm{l}, 3.66 \mathrm{~g} / \mathrm{l}$, and $7.32 \mathrm{~g} / \mathrm{l}$.and $10.98 \mathrm{~g} / \mathrm{l}$ Cadmium (11) ion solution respectively. Four conical flasks each labelled with appropriate initial concentrations of Cadmium (11) ion solution were set up. Ten (10 ml) of each concentration of the solution was measured out and taken into the appropriate flask, one hundred gram each of banana peels was weighed out, each and added into each of the four flasks each shaken for to mix , and each allowed a contact time of 25-minutes each. At the end of each contact intervals each of these four flasks was filtered into a labelled reagent bottle each using N0 40 what-man filter paper assisted with suction pump.

Atomic Absorption Spectrometric Analysis: All the filtrates from each of the sixteen experimental units were analysed at $229 \mathrm{~nm}$ wavelength for Cadmium (11) ion using AAS spectrometer (unicam model 969)

\section{RESULTS AND DISCUSSION}

The sorption of Cadmium (11) ion from aqueous solution using two edible fruit waste biomass was studied .The experimental data derived from this study was then modelled using Langmuir and Dubinin -Radushkevich isotherm equations respectively. The results obtained are presented in tables (1, and 2) figures 1,2 , and 3 respectively. From table 1 it was observed that the two edible fruit wastes each sorbed more than ninety -four percent of the initial concentration of the Cadmium (11) ion from the aqueous solution. Figure 1 showed the effect of concentration on the sorption capacity of each of this biomass for Cadmium (11) ion at constant biomass weight. The graph obtained showed a straight line which implies that increasing the Cadmium (11) ion initial concentration increases the sorption rate. The banana peels responds more positively as continue increase results in continue sorption without reaching saturation limit at the specified contact time of 25minutes used for each sorption studies. But this was the reverse in the case orange peels as saturation limit was reached within 25-minutes intervals 
(Table1). Figure 2 depicted Langmuir plot .It was from this plot that the maximum sorption capacity of each of these edible fruit waste biomass was calculated (Table 2). The orange peels gave highest sorption capacity of $148.67 \mathrm{l} / \mathrm{g}$ whereas the banana peels gave the least value (Table2). The figure 3 showed the Dubinin-Radushkevich plot. It was this plot that the porosity value of each of these edible fruit wastes was determined as well as the apparent sorption energy of each of this waste biomass (Table 2). The banana peels gave also the greatest porosity value of $Q_{D} 13.46 \mathrm{~g} / \mathrm{l}$ and the orange peels again gave least porosity value. This observation probably explained why banana peels do not attain a saturation equilibrium limit within the 25-minutes intervals whereas the orange peels do. The orange peels gave the largest sorption energy of E 0.245 calories per mole of Cadmium (11) ion (Table 3 ). It is therefore suspected from this observation that the sorption of Cadmium (11) ion by these edible fruit waste biomass is energy dependent. In conclusion therefore the three parameters determined namely maximum sorption capacity $Q_{\max }$, porosity $\mathrm{Q}_{\mathrm{D}}$, and the apparent free energy $E$ of sorption have to be taken into consideration whenever these biomass are to used as metal ion sorbent materials especial for the removal of Cadmium (11) ion from the aqueous solutions like waste waters industrial effluents and agricultural run off waters.

Table1: Parameters obtained from the sorption studies of edible fruit waste biomass

\begin{tabular}{|l|l|l|l|l|l|l|}
\hline Biomass & Ceg/l & Qeg/l & Ce/Qe & InQe & RTIn(1+1/Ce) & \%Sorption \\
\hline Banana peels & 1.83 & 1.725 & 1.061 & 0.545 & 90.616 & 94.26 \\
\hline Banana peels & 3.66 & 3.578 & 1.0172 & 1.280 & 50.207 & 98.31 \\
\hline Banana peels & 7.32 & 7.284 & 1.005 & 1.986 & 26.616 & 99.51 \\
\hline Banana peels & 10.98 & 10.948 & 1.0039 & 2.393 & 18.117 & 99.71 \\
\hline Orange peels & 1.83 & 1.75 & 1.046 & 0.560 & 90.616 & 95.63 \\
\hline Orange peels & 3.66 & 3.60 & 1.017 & 1.281 & 50.207 & 98.86 \\
\hline Orange peels & 7.32 & 7.24 & 1.011 & 1.980 & 26.616 & 98.91 \\
\hline Orange peels & 10.98 & 10.76 & 1.0204 & 2.377 & 18.117 & 98.00 \\
\hline
\end{tabular}

Values are means of four determinations

Table2: Data obtained from the modelling using Langmuir and Dubinin-Radushkevich equations

\begin{tabular}{|l|l|l|l|l|l|}
\hline Biomass & Qmaxl/g & Klg/l & $Q_{D} / /$ & $-B_{D}$ Calories & E calories \\
\hline Banana pees & 100.00 & 1.009 & 13.46 & 17.50 & 0.169 \\
\hline Orange peels & 148.67 & 1.010 & 11.023 & 8.34 & 0.245 \\
\hline
\end{tabular}

Values are means of three determinations

\section{Effect of concentration variation}
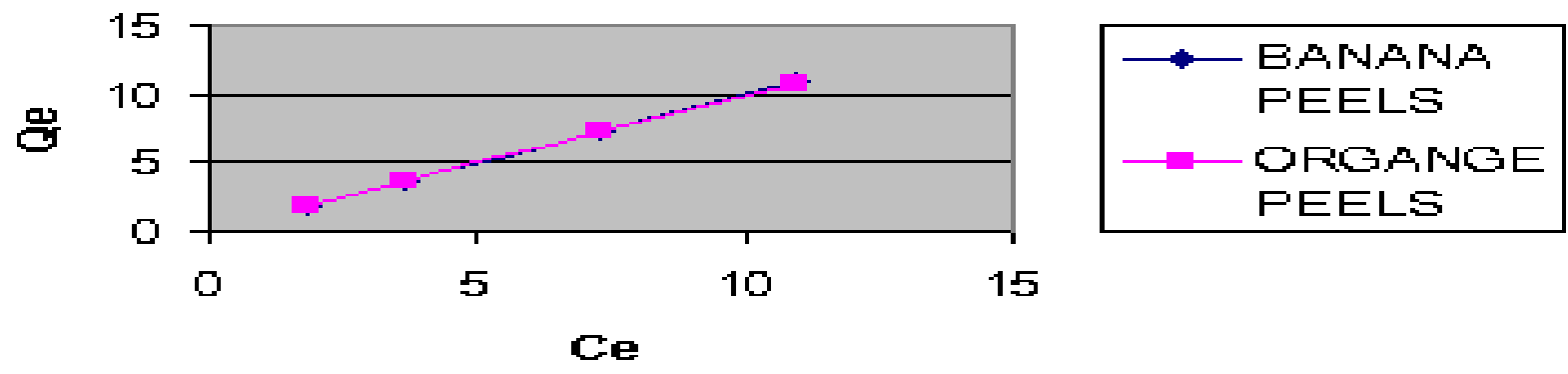

Fig 1: Effect of concentrations variation 
Am. J. Sci. Ind. Res., 2011, 2(3): 386-390

\section{langmuir model}
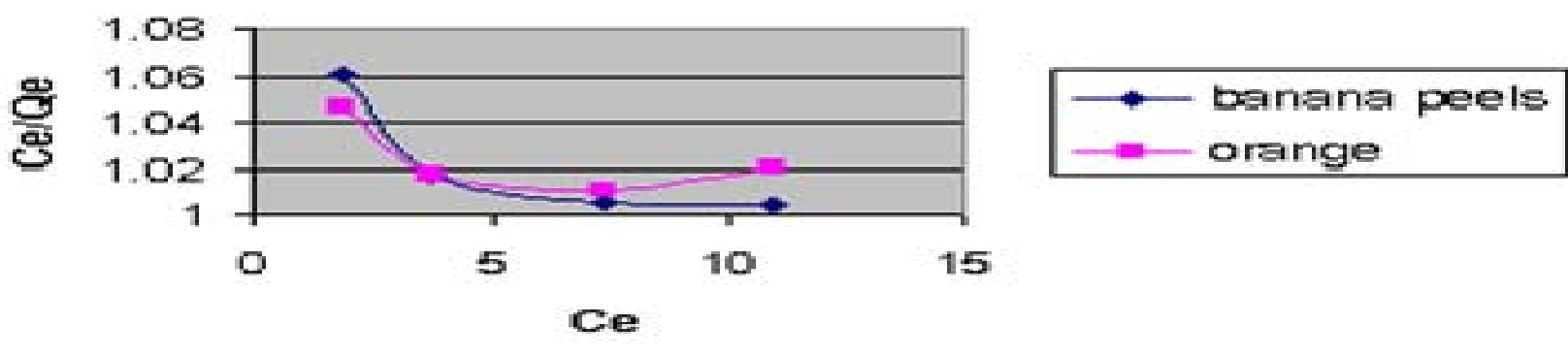

Fig 2: LANGMUIR MODEL

\section{Dubimin-Radushkewich model}
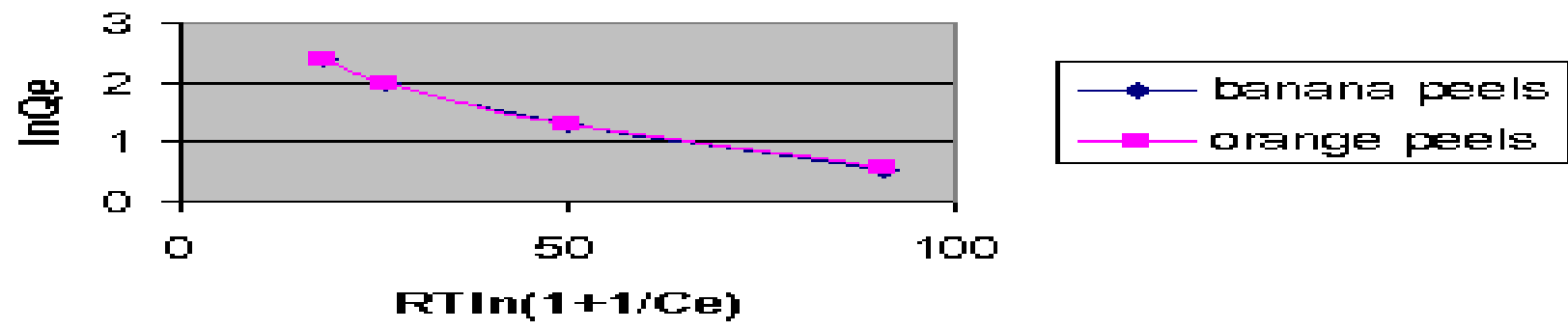

Fig 3: Dubinin-Radushkevich model

\section{REFERENCES}

1. Keith L H. and Tellard W. A (1979); Priority pollutants.Environ.Sci.Technol.13 416-424

2. Igwe J.C and Abia A,A (2006):Sosptin kinetics and intraparticulate diffusivity of As(11) bioremediation from the aqueous solution using modified and modified cassava fibres.Ecl.Quim Sao Paulo 31 (3) 23-29.

3. Kumar M Rathore D P S and Sing A.K (2000): Toxic effect of heavy metals to human and environments. Talanta51 1186-1187.

4. Gayer R.A (1994) ; Toxic effect of metals in casaret and doulls toxicology ,the basic science of poison $4^{\text {th }}$ edition Amdur D. klassen(editor) Pergamon press New York pp 14-28

5. Correa P.R.M Olivera E and Olivera

P.V.(2000)Public health and accumclation of $\mathrm{Cd}$ and $\mathrm{Pb}$ in human organs .Anal.chim.Acta 405 204-205.

6. Amorim F, Polito W.L Olivera S.RFreschi GPG. And Gomes neto J .A (2006): Simultaneous determination of $\mathrm{Cd}$ andPb in antibiotics used in sugar cane fermentation process by GFAAS.Ecl.Quim.sao Paulo 31 (2) 7-12.
7. Tyler T.G.(1981):Heavy metals in soil biology and biochemistry.In soil biochemistry Marcel dekker publishers Itd New York, pp31-33.

8. Bergman U (1983): Metal speciation and toxicity of free metal ion to aquaticbiota.In Nriagu J.O (editor) Aquatic toxicity .Adv, environ,sci.techn. John wilily and sons, New York, 13 47-73.

9. Okorol.A andEjike E, N (2007): Sorption models of lead (11) ion onto edible fruit waste biomass. European Journal of Scientific Research VOL17 270276

10. Osu C.I and Odoemelam S.A (2007): Heavy metals $(\mathrm{Pb}, \mathrm{Cd}, \mathrm{As}$, and $\mathrm{Hg}$ ) contamination of edible grains grown and marketed in Nigeria.Res.J.Applied Sci.2 (2) 192-195.

11. Weiner E.R (2000) Application of environmental chemistry .A practical guide for environmental professionals. Lewis publishers New York, pp84-85.

12. Igwe J.Cand Abia A.A (2005): Sorption kinetics and intraparticulate diffusivity of $\mathrm{Cd}, \mathrm{Pb}$, and $\mathrm{Zn}$ ions on maize cobs. Afr.J.Biotechnologyvol4 (6) 509-512. 
13. Igwe J.C and Abia A.A (2006): A bio separation process for removing heavy metals from waste water using biosorbents. Afr.J. Biotechnology vol5(12) 11671179

14. Igwe J.C and AbiaA.A (2003) :Maize cob and husks as adsorbents for the removal of $\mathrm{Cd}, \mathrm{Pb}$ and $\mathrm{Zn}$ ions from waste water .Pysical.Sci.(2) 83-94

15. Abia A,A Horsfall $M$ and Spiff A.I (2004): Studies on the influence of mercepto-acetic acid on modified cassava waste biomass on adsorption of $\mathrm{Cu}^{2+}$ and $\mathrm{Cd}^{2+}$ from aqueous solution .Bulletin of Korea chemical society vol25(7) 969-976.

16. Horsfall M and Spiff A.I (2004) Studies on the effect of $\mathrm{pH}$ on sorption of $\mathrm{Pb}^{2+}$ and $\mathrm{Cd}^{2+}$ ions from aqueous solution by caladium bicolour (wild cocoyam) biomass .Electronic J Biotechnology (online) 15 December vol 7 No 3 1-11. 